
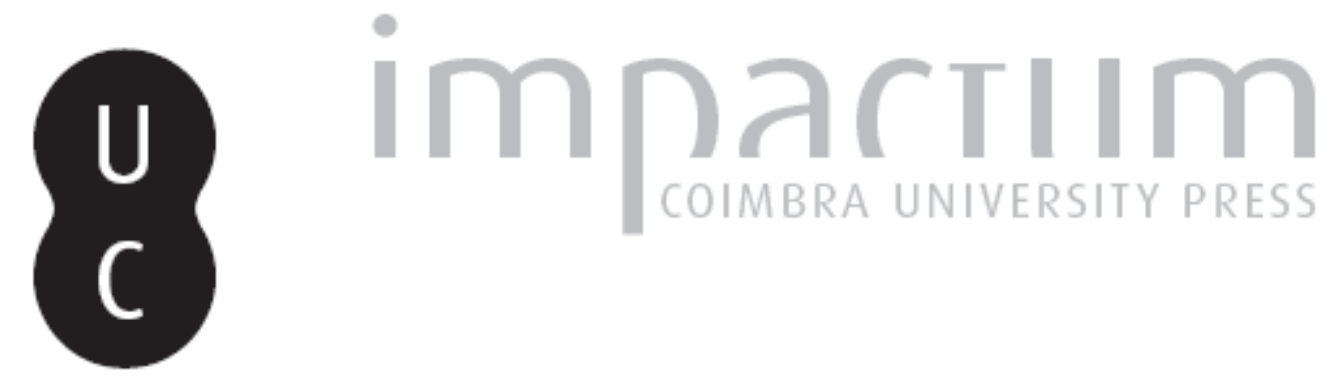

Andrea Pozzo: difusão científica e alinhamento do imaginário arquitectónico

Autor(es): Cabeleira, João

Publicado por: Imprensa da Universidade de Coimbra

URL persistente:

URI:http://hdl.handle.net/10316.2/44974

DOI:

DOI:https://doi.org/10.14195/0870-8584_12_11

Accessed : $\quad$ 26-Apr-2023 12:38:16

A navegação consulta e descarregamento dos títulos inseridos nas Bibliotecas Digitais UC Digitalis, UC Pombalina e UC Impactum, pressupõem a aceitação plena e sem reservas dos Termos e Condições de Uso destas Bibliotecas Digitais, disponíveis em https://digitalis.uc.pt/pt-pt/termos.

Conforme exposto nos referidos Termos e Condições de Uso, o descarregamento de títulos de acesso restrito requer uma licença válida de autorização devendo o utilizador aceder ao(s) documento(s) a partir de um endereço de IP da instituição detentora da supramencionada licença.

Ao utilizador é apenas permitido o descarregamento para uso pessoal, pelo que o emprego do(s) título(s) descarregado(s) para outro fim, designadamente comercial, carece de autorização do respetivo autor ou editor da obra.

Na medida em que todas as obras da UC Digitalis se encontram protegidas pelo Código do Direito de Autor e Direitos Conexos e demais legislação aplicável, toda a cópia, parcial ou total, deste documento, nos casos em que é legalmente admitida, deverá conter ou fazer-se acompanhar por este aviso. 


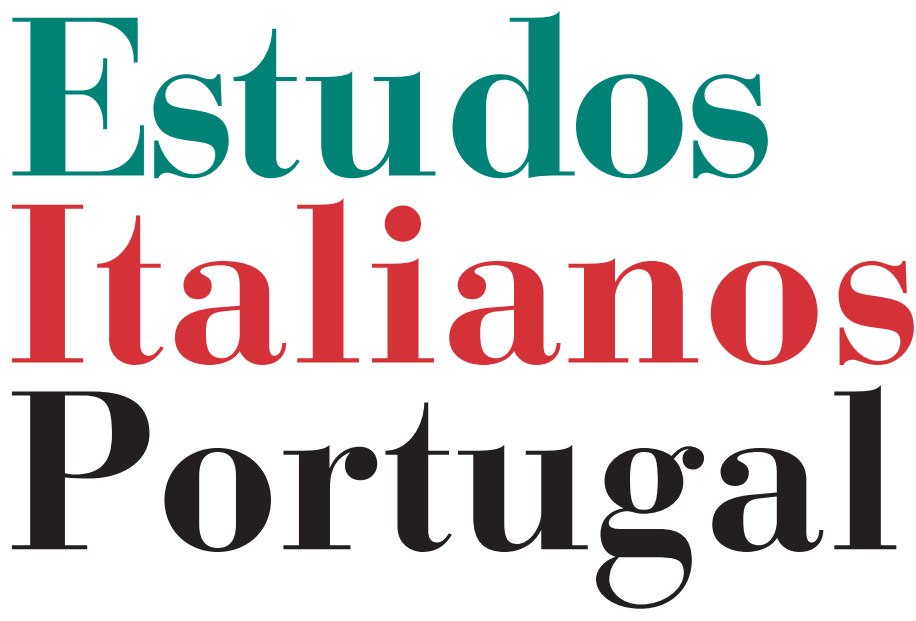

Instituto

Italiano

de Cultura

de Lisboa

Nova Série

No 12

2017 


\title{
ANDREA POZZO. DIFUSÃO CIENTÍFICA E ALINHAMENTO DO IMAGINÁRIO ARQUITECTÓNICO
}

\author{
JoÃo CABELEIRA*
}

EMBORA NUNCA TENHA PISADO SOLO lusitano, ou se registe algum contacto com os agentes científicos e artísticos em Portugal, é inegável a influência do jesuíta italiano Andrea Pozzo (1642-1709) sobre o panorama nacional de setecentos. Uma influência que ressoa no âmbito da produção artística (da cenografia à quadratura passando pela arquitectura e artes decorativas) e sistematização científica (referente à perspectiva linear) a partir do seu tratado Perspectiva pictorum et architectorum (1693-1700). Uma obra que, fundada na excelência das ilustrações e clareza explicativa da construção perspéctica e suas aplicações demonstradas na investigação artística do autor, rapidamente, e em muito potenciado pela máquina propagandística jesuíta, se propaga por todo o espaço católico.

$\mathrm{Na}$ abertura do primeiro tomo, Pozzo interpela directamente o leitor esclarecendo-o dos objectivos da obra - a instrumentalização da perspectiva no engano do olhar: "A arte de perspectiva, com prazer admirável, engana o mais consciente dos nossos sentidos externos que é o olhar" (Pozzo

* Professor Auxiliar da Escola de Arquitectura da Universidade do Minho, responsável pelas disciplinas de Geometria e História da Arquitectura II, e membro do Lab2PT. Os seus interesses incidem na tratadística arquitectónica/perspéctica e representação moderna do espaço no encalce da investigação "Arquitecturas Imaginárias: Espaço real e ilusório no Barroco português". joaocoelho@arquitectura.uminho.pt 
1693: 3). Expondo a capacidade propositiva da perspectiva linear na transformação do espaço, Pozzo explora os domínios da representação enquanto campo de acção arquitectónica, visando a criação de aparatos espaciais totalizantes (como a quadratura e a cenografia) onde o representado interfere indelevelmente no espaço habitado pelo observador: mecanismos verosímeis capazes de dar a ver uma nova realidade.

\section{A CIÊNCIA PERSPÉCTICA}

A recepção de Perspectia pictorum et architectorum em Portugal deve muito a Inácio Vieira que difunde os conteúdos teóricos e imagéticos da obra na sua Licção da Aula da Sphera do Colégio de Santo Antão de Lisboa. A par deste José Sanches, Perspectiva matemática assombrada aos rayos (1716), e Inácio da Piedade Vasconcellos, Artefactos symetriacos e geométricos (1733), citam o autor italiano a propósito da teoria das ordens, ao mesmo tempo que o tratado é traduzido para português, embora permanecendo inéditas.

Das traduçóes empreendidas, a Perspectiva de pintores \& architetos (1732) revela, a par do texto de Pozzo, anotaçóes e acréscimos esclarecendo sequências operativas na delineação da imagem quadraturista, chegando à enunciação de uma Nova explicação. Na sua essência, esta Nova explicação pelo pintor e arquitecto Figueiredo Seixas não é indiferente às gravuras de Pozzo que, por circunstancialismos na comunicação de uma sequência de acções, se organizam sob quatro quadrantes expondo em simultâneo diferentes fases do processo. Uma explicação, que remete ainda ao discurso de Vignola/ Danti (1583), o qual, face à execução da quadratura para a Sala Bolonha (1575, Vaticano), concretiza o modelo a partir de $1 / 4$ da composição.

Mais literais são o Libro de prespectiva e hé tamben de architetura (1768), empreendido por Frei José Vilaça, pintor, 


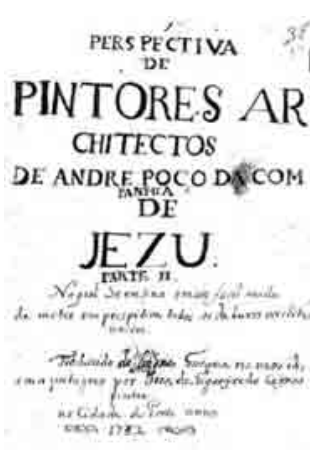

Fig. 1 José de Figueiredo Seixas, Perspectiva de pintores \& architetos (1732), frontispício.
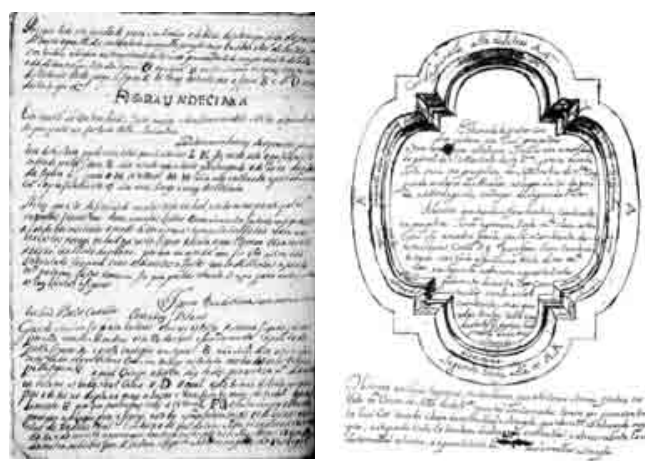

Fig. 2 Frei José de Santo Fig. 3 Anónimo, PrimeiAntónio Vilaça, Libro de ra parte de prospectiva de prespectiva e hé tamben de pintores e arquitectura (c. architetura (1768), fig. 11. ${ }^{\mathrm{a}}$. 1730-1745), fl. 110v

escultor e entalhador beneditino sediado no mosteiro de Tibães, e a Primeira parte de prospectiva de pintores e arquitectura (c. 1730-1745), a qual inclui anotação de desenho relativa a tecto de Simões Ribeiro para a igreja de São Martinho (c. 1719, Santarém), a par de uma digressão por assuntos relativos à escultura.

Porém, desta Primeira parte de prospectiva, não se identifica de modo incontestável o autor, podendo ter sido realizada no interior da Casa Professa ou ser resultado da necessidade de algum pintor interessado na quadratura. Nesta lógica, Raggi (2004) atribui o documento a Luís Gonçalves Sena, pintor escalabitano, dada a proximidade entre os esquemas de Pozzo e a sua quadratura para a igreja do Colégio da Companhia em Santarém. Por sua vez, Serrão (2003) avança que a tradução poderia ter sido realizada por membro de academia literária da cidade, propondo-se a identificá-lo com o Padre Manuel Pereira, um curioso de arquitectura da era joanina. Porém, apesar das diferenças, os dois historiadores concordam que a tradução resultará do influxo gerado a partir do Colégio Jesuíta de Santarém. 
É sob essa ideia que consideramos a hipótese da sua tradução por Inácio da Piedade de Vasconcellos que, sendo de origem escalabitana, frequenta o colégio da Companhia, publica sobre matérias do desenho e instrumentalização da geometria à prática artística e tem prática na escultura em barro e metal.

A tradução segue a sequência dos tomos I (fls. 2r-48r) e II (fls. 58v-88v) de Pozzo, sem apresentar ilustrações, à qual se segue o Modo de fazer figuras de barro (fls. 90v-91r); Trata das advertências com que se hamdem fazer as figuras de pasta (fls. 91r-93v); Trata das figuras que se houverem fundir ouças em qualquer metal (fls. 93v-98r). Uma digressão pela escultura que, sendo alheia à obra de Pozzo, será também uma tradução, já que se menciona um primeiro capítulo do livro, "como já disemos no primeiro capitulo deste livro" (fl. 90v). Ora, é a partir da inserção desta matéria que se fundamenta a atribuição do manuscrito a Piedade Vasconcelos. Assim, associa-se ao documento um autor coincidente com a sua execução no espaço (Santarém), filiação (comunidade inaciana escalabitana), tempo (década de 30-40 do século XVIII) e sincronia de interesses (ciência geométrica e escultura).

Porém, a recepção do tratado de Pozzo em Portugal coincide com a formulação de trabalhos de monta na ordenação da ciência perspéctica. Neste processo, o Tractado de prospectiva (1716) por Inácio Vieira actualiza o conhecimento em perspectiva, vinculando-se às ilustrações, enunciados e sequência operativa de Pozzo (ainda que não seja a única fonte), valorizando claramente lógicas imagéticas que permitem, a partir da pintura, quadratura e cenografia, a conformação de simulacros espaciais e exortando a maravilha da natureza e o prodígio da produção artística e científica no engano do olhar.

Nesta articulação entre ciência perspéctica e a imagem do espaço barroco, Vieira não deixa de expor um artigo dedi- 

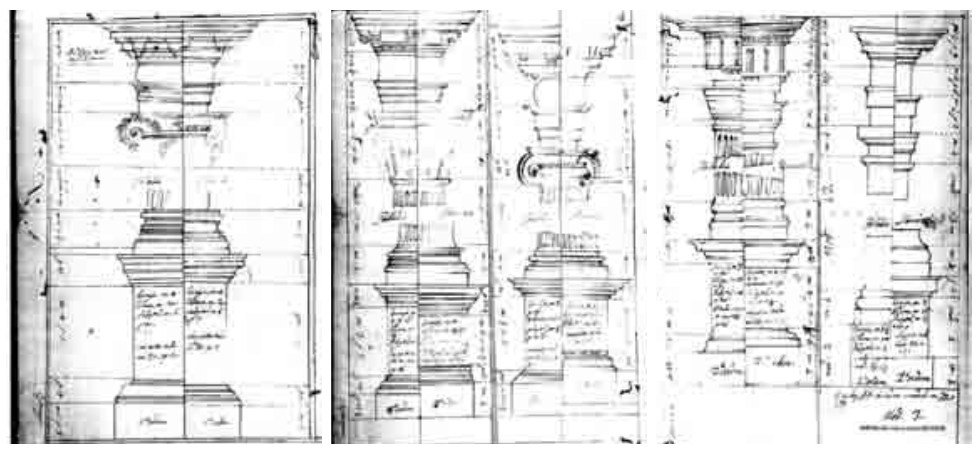

Fig. 4 Inácio Vieira, Tractado de prospetiva (1716), estampas s. n.

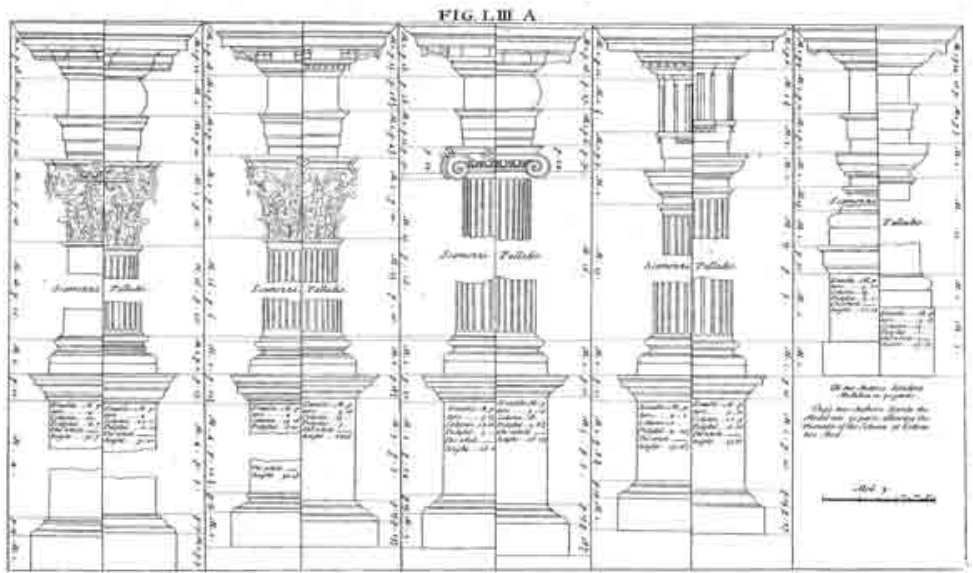

Fig. 5 Andrea Pozzo, Perspectivæ pictorum et architectorum (1693, Roma), figura s. n.

cado à arquitectura e regras de composição, que intitula de Digressão opportuna da architetonica civil (fl. 090). Um desvio aos conteúdos da perspectiva justificados por:

[...] não poder dar hum passo sem conhecer os princípios porporçoens, e medidas das cinco ordens, q[ue] a Architetura Civil comprehende não merecerá assim tomar quem $\mathrm{p}$ [ar]a servir a coriozid[ad]e; e formar hu perspetico tratar juntam[en] te da Architetonica; pois todos sabemos, q[ue] a perspetiva tida se empenha em formar em plano com cores, e pincel a valentia da Architetura, expondo com todos resaltos 
e sacadas, medidas, e porporçoens, o q[ue] o architeto mais destro pôs em sólido $\mathrm{p}[\mathrm{ar}] \mathrm{a}$ admiração da arte, e ornato dos edifícios, e gostozo galenteio da vista.

(Vieira 1716, fls. 090-091)

O autor inspira-se em Pozzo que nos Avvisi ai principianti refere que a prática da perspectiva exige o reconhecimento do desenho da arquitectura, replicando a estampa de Pozzo relativa a Ordines architecturae, desumpti ex Palladio o Scamozzie.

\section{O teatro À italiana. Cenografia e máquinas de cena}

A par da recepção do tratado de Pozzo, importa considerar, logo no início do século XVIII, a acção simultânea em Lisboa de dois mestres italianos: Bacherelli, que introduz na capital a novidade da grande ilusão quadraturista; e de D. Agostinho, que parece promover o modelo da cenografia italiana no seio da Companhia de Jesus.

Ainda que se desconheçam dados concretos acerca da origem, formação e filiação artística de D. Agostinho (porventura consequente ao carácter efémero da obra, senão mesmo da sua estadia em Lisboa), este é mencionado por Vieira como pintor italiano chegado por via do séquito de Maria Ana de Áustria e que pinta o cenário da ópera levada a cabo no Colégio de Santo Antão, por ocasião das bodas de D. João V. Sabendo que Pozzo exerce actividade em Viena entre 1703 e 1709, ao serviço do Sacro Imperador Leopoldo I (pai de Maria Ana de Áustria), parece-nos pertinente lançar algumas questões.

Poderá este pintor italiano ser forjado na esteira de Pozzo? Se, por um lado, temos a possibilidade de uma coincidência geográfica e temporal, também Vieira aponta nesse sentido ao afirmar, "Em esta forma dispozemos estas senas, e este teatro, tirado em p[ar] te do irmaó Posso" (Viei- 
ra 1716: fl. 320). Se a elaboração das cenas parece assim orientar-se sobre o tratado de Pozzo, sabemos também que Bacherelli quisera tomar a obra, mas terá sido D. Agostinho a terminá-la. Mas se este a terminou, quem seria o autor do desenho?

À parte estas questões, não deixa de ser relevante a incursão de Vieira por Das senas theatrais do Irmão Posso na pr[imei] ra p[ar]te (fl. 307), e Das mesmas senas theatrais do d[it]o Autor na 2. ${ }^{a}$ p [ar]te (fl. 312). Uma inclusão que não é alheia à dinâmica pedagógica da Aula da Sphera, onde a dramaturgia permite concretizar matérias ministradas como a teologia, retórica, óptica, perspectiva e mecânica.

Vieira explora, a partir de Pozzo, a configuração do teatro à italiana e expõe esquemas da delineação cenográfica, como o da aceleração do espaço, conformada a partir da disposição troncocónica de pernas e telão de fundo e projecção, com recurso a malhas, da desejada imagem ilusória estruturada pela perspectiva. Contudo, se a abordagem é estritamente geométrica, no suporte à projecção perspéctica e aceleração espacial, em Da mudansa do teatro (fl. 316) Vieira explora os diferentes tipos de cena (trágica, cómica e satírica), apoiando-se no discurso de Daniel Barbaro (1568), e descreve a cenografia de Tergemina Austriacae Aquilae Corona, realizada por ocasião das bodas do Magnânimo. Do discurso, ressalta a elaboração de três mudanças totais de cena (sala, bosque e cidade) e outras parciais (por exemplo, a partir do bosque gera-se uma imagem do inferno, de jardim e outra de campo). Mas, mais do que a descrição do aparato cenográfico, sobressaem questóes acerca da mecânica de cena.

Então, porquê este entusiasmo em matéria exterior à perspectiva? Se, por um lado, a tragicomédia exigia uma complicada maquinaria de suporte, por outro, a ênfase do discurso na primeira pessoa leva-nos a crer que Vieira terá participado, ou sido responsável, pelos mecanismos aplicados aquando dos festejos das bodas reais. 

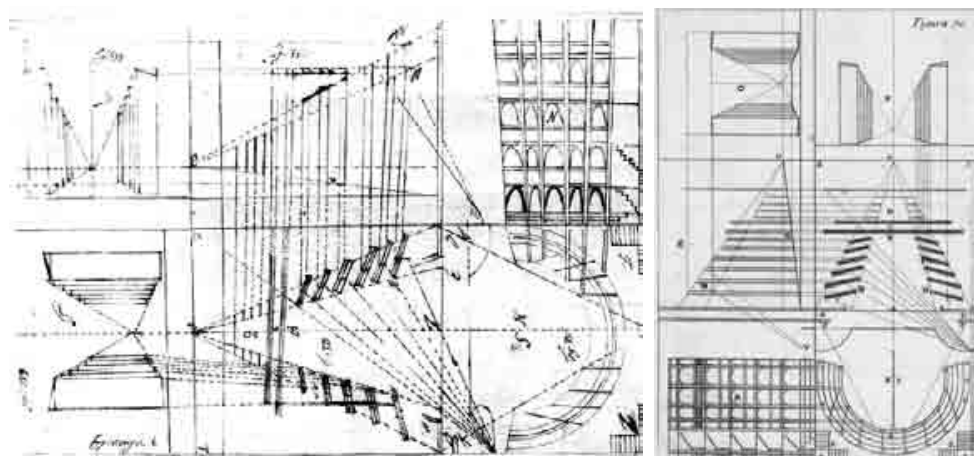

Fig. 6 Inácio Vieira, Tractado de prospetiva (1716), Fig. 7 Andrea Pozzo, Persestampa s. n.

pectiva pictorum et architectorum (1693, Roma), figura $72 .^{\mathrm{a}}$, De i teatri scenici.

Ainda assim, e à parte o esclarecimento da autoria dos cenários ou máquinas de cena de Santo Antão, é certa a influência de Pozzo na definição do espaço teatral à italiana e em estratégias de implementação da grande ilusão cenográfica. Aliás, a cenografia e delineação de aparatos efémeros assume tal importância, no suporte retórico à imagem triunfante da igreja e na afirmação áulica da corte, que esta será amplamente explorada pelos artistas/arquitectos italianos em circulação por Portugal, como Filippo Juvarra, António Canevari ou Nicolau Nasoni.

Formulário QUADRATURISTA. IMAGINÁRIO E CONFORMAÇÃo DO ESPAÇO TOTAL

Se a historiografia acerca da teoria, prática e vias de influência quadraturista se concentrou na polaridade entre a acção de Bacherelli e a influência do tratado de Pozzo, essa visão é desajustada face ao número de autores e fontes a circular em Portugal, assim como à variedade de opções técnico-artísticas por parte dos autores nacionais. Uma polaridade 
corrigida por Mello (2003) e Raggi (2004), que desbravaram o acervo quadraturista, montando a teia relativa à recepção e absorção da quadratura, a rede de relações entre autores, patronos, modelos, conteúdos iconográficos e simbólicos, a par da valorização da autonomia do género. Por outro lado, Reis (2006) amplia essa inventariação e aborda relações entre a experiência perceptiva, metafísica e intelectual do espaço quadraturista, enquanto Trindade (2008) abre caminho à análise de conteúdos da geometria e Cabeleira (2015) aprofunda o reconhecimento de valores projectivos e remete às valências arquitectónicas do género, nomeadamente a síntese percebida (entre construído e representado), averiguando interferências da quadratura sobre o espaço habitado.

De facto, sendo inegável o referente italiano na implementação desta modalidade imagética e espacial, a prática nacional é resolvida no hibridismo resultante da acção de distintos mestres italianos, a par da absorção de conteúdos teóricos e imagéticos por via da tratadística especializada. Porém, propondo-nos perseguir a influência de Pozzo em Portugal, individualizamos, de entre os autores nacionais, Lourenço da Cunha, Luís Gonçalves de Sena, José Ferreira da Rocha e Manuel Xavier Caetano Fortuna.

A obra de Lourenço da Cunha molda-se à estética pozziana assimilada na sequência das suas viagens a Roma. Vertida essa influência nas quadraturas da igreja do Santuário de Nossa Senhora do Cabo (1740, Cabo Espichel), o primeiro nível das arquitecturas imaginárias delineadas na abóbada alinham-se com o tratado de Pozzo, enquanto a composição do nível superior não encontra paralelo na obra do jesuíta italiano. Uma distinção consequente à intervenção por José de António Narciso que, na sequência do terramoto de 1755 , pinta e redesenha a porção danificada.

Esse primeiro nível corresponde à porção entre sanca da nave do templo e sofito do balcão ilusório, compreendendo as mênsulas que anulam a curvatura da abóbada e distanciam 


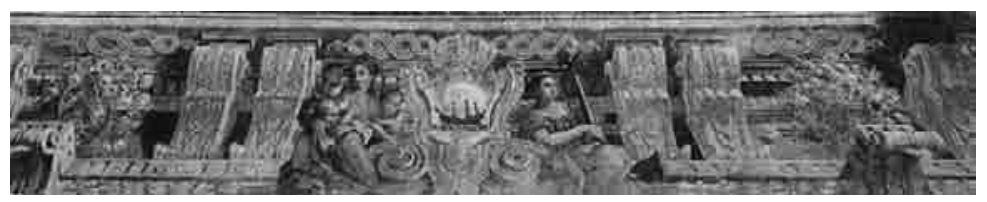

Fig. 8 Lourenço da Cunha, Nossa Senhora do Cabo (1740, Cabo Espichel).

a galeria ilusória. Um elemento de reorganização e coordenação entre os ornamentos construídos e representados que detém a responsabilidade máxima na elevação do espaço ilusório e cujo efeito é potenciado pelo contraste da aparência material (o dourado das mênsulas face ao fundo ensombrado azul) e da modelação luminosa (concordante com o sentido de penetração da luz natural e percurso do observador).

Mas se a actuação de Lourenço da Cunha actua junto do círculo de influência da corte, mais informado e de forte influxo italiano, a progressiva difusão do modelo pozziano para núcleos regionais vacila entre a sua adopção informada e a simplificação, redução e hibridação da técnica e do imaginário arquitectónico. Neste âmbito, Luís Gonçalves Sena revela ainda o domínio do imaginário pozziano, rearranjando o referente em função das circunstâncias espaciais em que intervém, enquanto José Ferreira da Rocha e Manuel Xavier Caetano Fortuna revelam a obediência absoluta às composições do tratado de Pozzo.

A quadratura de Luís Gonçalves Sena para a abóbada da capela-mor do Colégio Jesuíta de Nossa Senhora da Conceição (1754, Santarém) é talvez o exemplo mais pertinente do poder da tratadística na difusão técnica e imagética da quadratura, permitindo à comunidade inaciana de um núcleo regional implementar um programa imagético concordante ao da sua congénere romana.

Se a introdução do gosto quadraturista actualizado e informado tem, em Santarém, Simóes Ribeiro como principal agente, a meados do século XVIII a produção é definida por Sena, cuja obra marca o momento máximo da produção local 
e, simultaneamente, o fim deste tipo de operação imagética e espacial. Tendo a formação de Sena ficado circunscrita ao núcleo regional em que opera, a sua obra resulta, conforme Benedicto (1791), de um espírito autodidacta, orientado numa multiplicidade de géneros e informado pela tratadística especializada. É precisamente por esta via que o pintor adquire as competências para avançar na execução de perspectivas arquitectónicas, assimilando o modelo estético e técnico de Pozzo.

De facto, da observação da quadratura parece evidente a coincidência às formas e imagens difundidas pelo Tomo I da obra de Pozzo, e cujo acesso se afigura como seguro por parte da elite e a comunidade inaciana escalabitana.

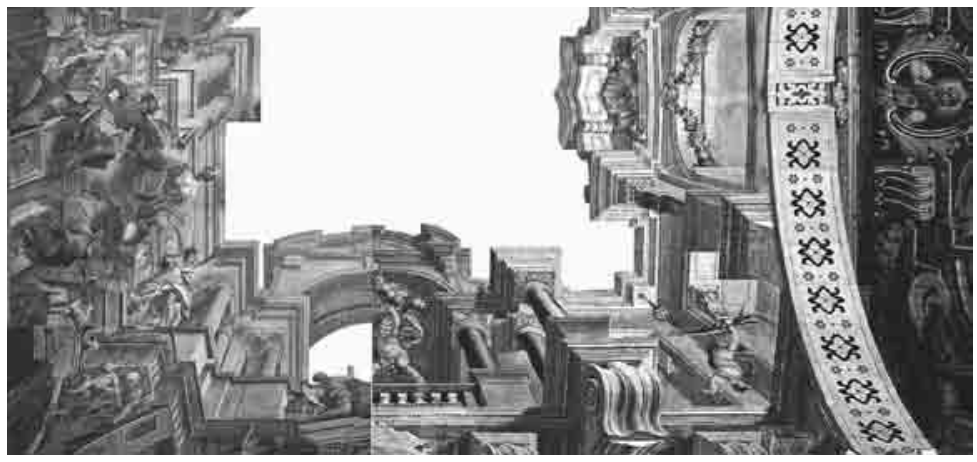

Fig. 9 Confronto entre a Entrada de Santo Inácio no Paraíso (1691-94) de Pozzo e a Assunção da Virgem (1754) de Sena, recortando o vazio central e comprimindo a altura da compressão nas colunas da imagem de Pozzo para ajuste dos elementos horizontais que definem a construção (pavimento da galeria, balaustrada, cornija e frontão).

$\mathrm{Na}$ obra é evidente a colagem de Sena às arquitecturas imaginárias que conferem espacialidade à Entrada de Santo Inácio no Paraíso (1691-1694). Uma filiação vinculada às figuras $98 .^{a}$ e $99 .^{a}$ do tomo I de Pozzo, evidente na simultaneidade de tratamento da balaustrada, modelação do arco e frontão, recorte e modinatura da cornija e ordenação das colunas coríntias. Contudo, o sincronismo detectado não é 
extensível à totalidade da imagem pelo que esta não corresponde a uma transposição directa e acrítica do modelo. Sena executa ajustes face às circunstâncias espaciais, seja ao nível de coadunação de escala (face à dimensão e configuração da superfície de suporte e espaço em que se integra a quadratura), como da resolução compositiva (reorganizando a planta e reconfiguração dos alçados, ainda que partindo de matrizes similares). Neste âmbito, atendendo à configuração do suporte pictórico, reduz-se a profundidade aparente do primeiro nível, que na obra de Pozzo servia à integração de lunetas e janelôes laterais, simplificado por Sena em função de mênsulas que balançam a construção ilusória e encetam a indução de impulso vertical. Por outro lado, na compatibilização de escala entre quadratura e espaço construído comprimem-se elementos da estrutura delineada, segundo uma redução proporcional dos factos, detectada por confronto entre a obra de Pozzo e a de Sena, que se verifica na compressão dos fustes do referente em $2 / 3$ da sua altura.

Perante isto, o autor revela capacidades de absorção e assimilação do formulário arquitectónico, de nítida filiação romana, integrando simultaneamente valores específicos da produção quadraturista e arquitectónica nacional. Sena verte assim sobre a imagem a experiência espacial e formal que caracteriza a contextura em que se move. Importante nesta sincronia é ainda a capacidade de, sobre o modelo apreendido, dotar as arquitecturas representadas de um espírito feérico mais próximo da matriz que domina o gosto e o modelo que emana a partir dos círculos eruditos da capital. Uma referência patente na proliferação de florões e grinaldas (suspensas dos arcos, como ornados de gala, ou ostentados por putti) ou na vibração cromática do conjunto que se coordena com a policromia das madeiras e embutidos marmóreos do espaço interno da capela.

Porém, em núcleos mais periféricos, cujos ecos da grande pintura espacial ressoam até finais do século XVIII, revela-se 
uma progressiva simplificação formal e técnica plasmada na repetição de fórmulas e composições anteriormente testadas ou no decalque directo de gravuras/tratados em circulação. Neste contexto, a obra de Manuel Xavier Caetano Fortuna manifesta o acesso à imagética pozziana, ainda que a dominância decorativa, já de gosto rococó, tente encobrir um parco domínio da perspectiva, nomeadamente no que se refere à projecção da estrutura arquitectónica delineada sobre a superfície de suporte.

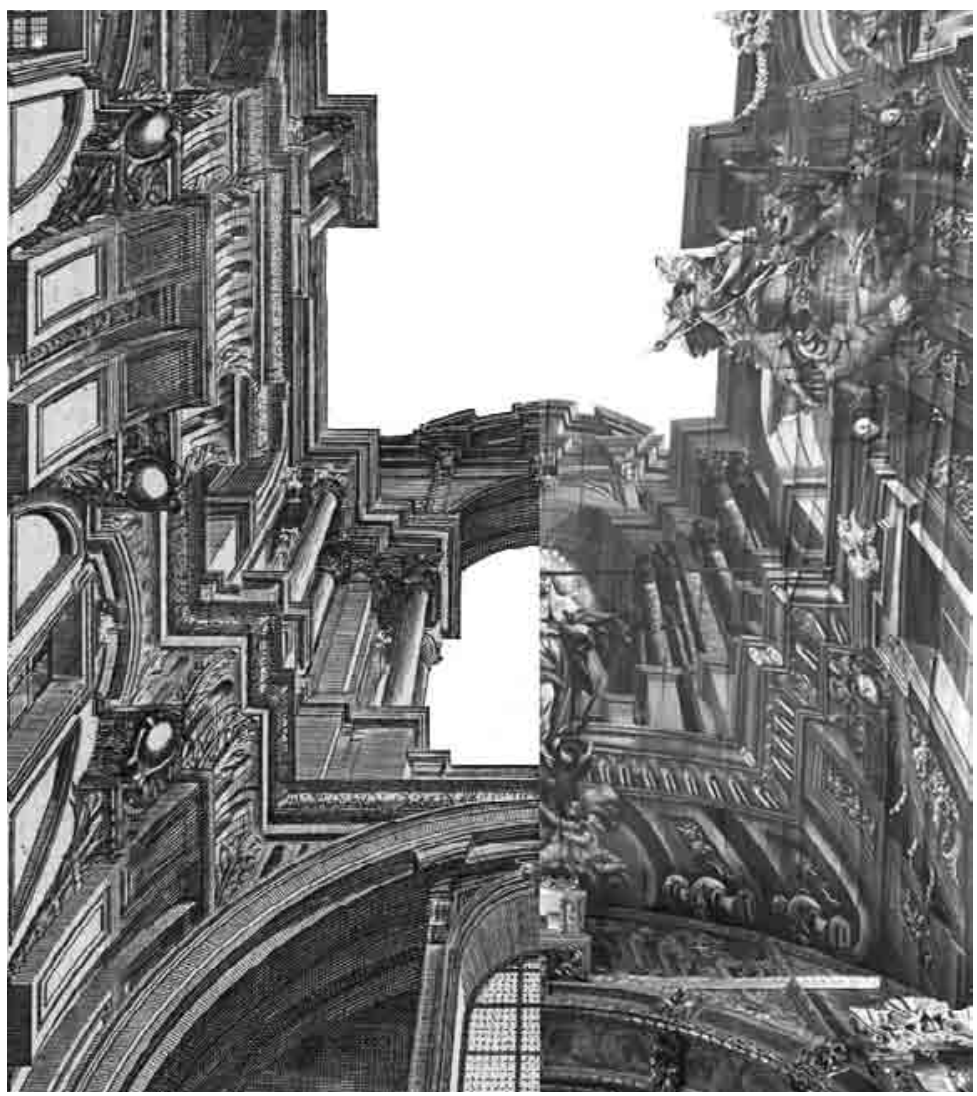

Fig. 10 Confronto entre a fig. 98. ${ }^{a}$ de Pozzo e a quadratura de St. ${ }^{a}$ Escolástica do convento de São Bento (1763) de Caetano Fortuna com ajuste do arco e frontão do eixo longitudinal da nave. 


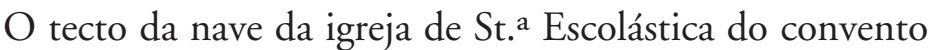
de São Bento (1763, Bragança) evidencia o decalque das gravuras de Pozzo, ainda que adapte a iconografia ao programa do templo. Com efeito, da observação desta quadratura resulta flagrante a sua coincidência com as figuras $98 .^{a}$ e $99 .^{a}$ do tomo I de Pozzo, assente numa concordância absoluta à matriz espacial, níveis de composição, modulação da composição arquitectónica e formulário aplicado. Ora, se no caso da quadratura de Sena esse sincronismo não é directo, ajustando-se o modelo às circunstâncias espaciais, operando uma recombinatória da gramática construtiva e repropondo a aparência do espaço, no caso do tecto de Caetano Fortuna a colagem ao referente é directa. $\mathrm{O}$ tecto da St. ${ }^{a}$ Escolástica reproduz inclusivamente o primeiro nível do espaço imaginário que, se em Roma servia à integração das lunetas nas quais se abrem os vãos que iluminam a nave, Caetano Fortuna repete, tal e qual a figura do tratado, representando as falsas janelas incluídas na figura do tratado de Pozzo.

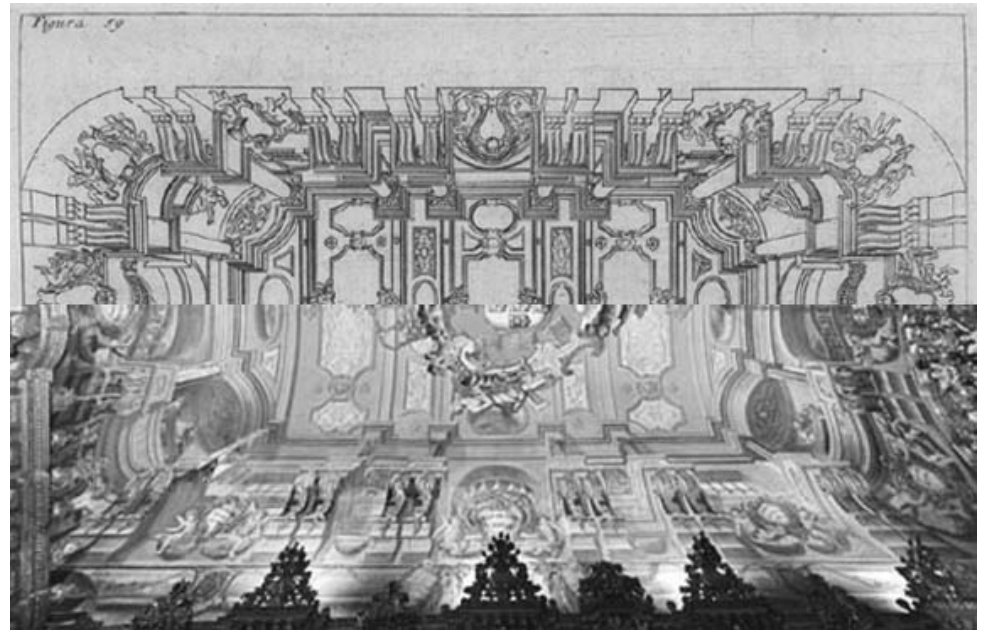

Fig. 11 Confronto entre a fig. 59. ${ }^{a}$ do tomo II de Pozzo e o tecto da Igreja de Santo António (c.1769, Lagos) de Ferreira da Rocha, com ajuste do arco das falsas tribunas do eixo longitudinal da nave. 
De modo similar, mas demonstrando um maior domínio da perspectiva e controlo da modelação pictórica, José Ferreira da Rocha (segundo atribuição de Raggi 2004) decalca no tecto da Igreja de Santo António (1769, Lagos), o espaço delineado na figura 59. a do tomo II de Pozzo. Uma estratégia que o mesmo autor aplica na igreja da Ordem Terceira do Carmo (1794, Faro), mas com o desenho das falsas arquitecturas do templo do Cabo Espichel, e do qual se diferencia apenas na resolução do óculo central.

Ainda que nesta exposição incidamos de modo mais particular na difusão da ciência perspéctica e do imaginário quadraturista, o qual é aceite como campo de experimentação arquitectónica, também no campo da construção e nas artes decorativas (nomeadamente na talha, a qual também é aceite como ensaio e via de disseminação de partidos arquitectónicos) a influência da Perpectiva pictorum et architectorum (1693) é um facto inquestionável. Porém, à parte a especificidade do formulário de Pozzo, que parece ressoar em todos estes domínios, o mais relevante parece ser a eficácia do seu tratado na difusão de um dos aspectos especialmente determinantes e caracterizadores do espirito da época, o domínio do espaço total.

\section{BibLIOGRAFIA}

Benedicto, Joaquim Duarte. 1791. Elogio do grande apelles portuguez, Luiz Gonçalves de Senna, Lisboa, Officina Patriarcal de Francisco Luiz Ameno.

Cabeleira, João. 2015. Arquitecturas imaginárias. Espaço real e ilusório no Barroco português, Tese de Doutoramento em Arquitectura apresentada à Universidade do Minho. Mello, Magno Moraes. 2002. Perspectiva pictorum. As arquitecturas ilusórias nos tectos pintados em Portugal no século XVIII, Tese de doutoramento apresentada à Universidade Nova de Lisboa.

Pozzo, Andrea. 2009. Perspectiva pictorum, et architectorum. Prospettiva de pittori, e architetti. Tomo I, Trento, Temi [1. ${ }^{\text {a }}$ ed. Roma, Giacomo Komarek Boemo, 1693].

Pozzo, Andrea. 2009. Perspectiva pictorum, et architectorum. Prospettiva de pittori, e architetti. Tomo II, Trento, Temi [1. a ed. Roma, Giacomo Komarek Boemo, 1700]. 


\section{I92 João Cabeleira}

Primeira parte de prospectiva de pintores e arquitectura. Mostrase o methodo mais fasil e espedito de deliniar com estilo prospetico, tudo aquilo que pertence a Arquitetura, inventado e [?], e primeiramente publicado em Roma, por Fr. Andre Poço, da Companhia de Jesus. Porem agora p. ${ }^{a}$ favor, e uzo dos estudiozos não muytos sientes desta Arte, se fes de velume mais piqueno, por João Boxbartlo, empresor. Anno 1719 [Santarém, manuscrito, c. 1719]. Raggi, Giuseppina. 2004. Arquitecturas do engano. A longa construção da ilusão, Tese de Doutoramento apresentada à Universidade de Lisboa.

Reis, Vítor dos. 2006. O rapto do observador. Invenção, representação e percepção do espaço celestial na pintura de tectos em Portugal no século XVIII, Tese de doutoramento em Teoria da Imagem apresentada à Universidade de Lisboa.

Seixas, José de Figueiredo. 1732. Prespectiva de pintores \& architetos [Porto, manuscrito].

Serrão, Vítor. 2003. História da Arte em Portugal, o Barroco, Lisboa, Presença.

Trindade, António. 2008. Um olhar sobre a perspectiva linear em Portugal nas pinturas de cavalete, tectos e abóbadas. 1470-1816. 2008, Tese de Doutoramento apresentada à Universidade de Lisboa.

Trindade, António Oriol. 2015. A pintura integrada em tecto e abóbadas e a perspectiva linear, Lisboa, Faculdade de Belas-Artes da Universidade de Lisboa.

Vasconcelos, Ignacio da Piedade. 1733. Artefactos symetriacos e geometricos, Lisboa, Joseph Antonio da Sylva.

Vieira, Inácio. 1716. Tractado de prospectiva [Lisboa, manuscrito]. 